\title{
Eine neue Methode zum Nachweis des Erstickungstodes mittels Untersuchung des Lungenblutes.
}

\author{
Von
}

Nobuyuki Kubo, Professor an dem pathologischen Institut der Sōtokufu-Igakkō in Taihoku, Formosa.

Über den Leichenbefund von Ertrunkenen liegen bereits zahlreiche Untersuchungen vor; aber abgesehen von den Erscheinungen des akuten Ertrinkungstodes sind spezifische Befunde für den Ertrinkungstod kaum zu verzeichnen. Einige davon sind Leichenerscheinungen, z. B. die sog. Gänsehaut und die Hautquellung an den Hohlhänden und Fusssohlen. Aúch der Nachweis von Ertränkungsflüssigkeit im Magen hat für die Diagnose des Ertrinkungstodes eine geringe Bedeutung. Flüssigkeit im Magen findet man in der Praxis in den meisten Fällen vor. Jedoch ist die Frage, ob das vorhandene Wasser vom Verunglückten verschluckt wurde, bevor er ins Wasser kam, oder ob ës erst während oder nach dem Ertrinken in den Magen gelangt ist, ist meist nur mit einiger Wahrscheinlichkeit zu entscheiden. Auch ist die Menge der Értränkungsffüssigkeit im Magen Schwankungen unterworfen.

i. Der Nachweis erheblicher Mengen von spezifischer Ertränkungsflüssigkeit in der Lunge, besonders in den Alveolen, wird immer für die Feststellung eines Ertrinkungstodes von Bedeutung sein. Lassen sich in den feineten Luftwegen Abortjauche, Spülflüssigkeit etc. nachweisen, só 
wird sich die Diagnose auch darauf stützen dürfen. Solche Fälle gehören jedoch zu den Seltenheiten, und anderseits treten nicht selten Fälle ein, bei denen es nicht gelingt, in der Lunge anatomisch oder mikroskopisch Ertränkungsflüssigkeit nachzuweisen, indem diese nur reines Wasser darstellt oder durch Fäulnisgas vertrieben oder vom Lungengewebe eingesogen wird. Wir haben daher Grund geung, immer aufs neue nach Anhaltspunkten für die Erkennung des Ertrinkungstodes zu fahden, da uns bis heute eben kein bestimmtes Anzeichen dafür zur Verfügung steht.

Eine charakteristische Erscheinung des Ertrinkungstodes ist das von Wachholz sogenannte Emphysema aquosum, d. i. trockene Blähung der Lungen, an denen sich ausser flüssigkeitsreichen, mit klarem Schaum durchsetzten Teilen hauptsächlich an den Rändern der vorderen und oberen Partien trockene Stellen mit erhöhtem Luftgehalt zeigen, was in einer grossen Zahl von Fällen deutlich żu erkennen ist.

A. Paltauf hat den Ertrinkungstod im Meerwasser auf chemischem Wege festzustellen versucht, und zwar hat er erwiesen, dass, wenn die Ertränkungsflüssigkeit aus Meerwasser besteht, sich in den Transsudaten der Lunge viel mehr Chlornatrium vorfindet, als in normalem Zustande. i

Brouardel, Viebert, Carrara und Andere beobachteten, dass die Ertränkungsflüssigkeit, die in die Lunge eingedrungen ist, durch die Lungenvenen bis ins linke Herz gelangt und dort eine Blutverdünnung hervorbringt. Sie hielten diese Erscheinung für ein Erkennungszeichen des Ertrinkungstodes; und auch Paltauf vertrat auf Grund genauer Untersuchungen mit dem Fleischl'schen Hämometer dieselbe Ansicht.

Carrara, welcher die Verdünnung des Herzblutes mittels Kryoskopie untersuchte, teilte mit, dass inbezug auf den Gefrierpunkt eine grosse Differenz zwischen dem Blut des rechten und dem des linken Herzens besteht. Ist die Ertränkungisflüssigkeit Süsswasser, so ist der Gefrierpunkt im linken Herzen höher als im rechten. Besteht die Ertränkungsflüssigkeit dagegen aus Meerwasser, welches, bekanntlich einen höheren Salzgehalt besitzt als das Blut, so tritt das Gegenteil ein, d. h. das Blut des rechten Herzens weist einen höheren Gefrierpunkt auf als das des linken 
Herzens. Ferner hat Carrara nachgewiesen, dass beim Ertrinken im Meerwasser die elektrische Leitfähigkeit des Blutes im linken Herzen grösser ist als im rechten.

Revenstoxf hat Versuche gemacht, um auf Grund hämolytischer Erscheinungen bei der Blutverdünnung am Ertrunkenen den Ertrinkungstod festzustellen.

Trotzdem die angeführten Verfahren zum Nachweis des Ertrinkungstodes meist nur ein negatives Resultat ergeben, so sind sie doch im allgemeinen wichtig und brauchbar.

Stumpf hat in der deutschen Gesellschaft für gerichtl. Medizin zu Königsberg i. Pr. (Sept. I9IO) über eine neue Methode zur Diagnose des Ertrinkungstodes berichtet. Er hat, gestützt auf die Tatsache, dass die Lungen von Ertrunkenen fast immer Blähung (Hyperämie, Emphysema aquosum ) aufweisen, Untersuchungen über die Tragfähigkeit der Lungen angestellt. Er legte die Lunge, nachdem er sie mit einem Tuch (z. B. Gaze) umgewickelt und daran kleine Bleistückchen befestigt hatte, ins Wasser und beschwerte sie, bis'sie zu sinken anfing, verglich alsdann das Gewicht der Bleistückchen mit dem Eigengewicht der Lunge und konnte so die Tragfähigkeit der letzteren berechnen. Die Untersuchung ergab Folgendes: Die Tragfähigkeit der Lunge eines Ertrunkenen verhält sich zum Lungengewicht ungefähr wie 3:2, während bei anderen Todesursachen die Lungentragfäh ${ }_{j}$ gkeit zum Lungengewicht ein Verhältnis wie I : 2 aufweist. Die Stumpf'sche Methode erscheint auf den ersten Blick einfach, aber es ist wohl anzunehmen, dass durch individuelle Differenzen in der Grösse, dem Gewicht und dern Gehalt an Luft, Blut und Serum das Ergebnis ein ungenaues wird. Tatsächlich hat Bohne durch eigene Versuche nachgewiesen, dass das Stumpf'sche Verfahren an Zuverläsigkeit einbüsst : I. bei faulen Leichen, 2. beim Verblutungstod, 3. bei Emphysem auch geringen Grades, 4. zum Teil bei Verwachsungen der Pleurablätter und 5. bei einigen unaufgeklärten Fällen. Aus diesen Gründen ist in der Praxis bei Anwendung dieser Methode grosse Vorsicht geboten.

Wie erwähnt, wissen wir nun, dass beim Ertrinkungstod durch die 
Lungen die Ertränkungsflüssigkeit bis ins linke Herz gelangen und einé Blutverdünnung zur Folge haben kann. Ich versuchte deshalb das spezifische Gewicht des Blutes vom linken und rechten Herzen einer Prüfung zu unterziehen und so den Ertrinkungstod zu diagnostizieren.

Schon früher hat Placzeck Versuche nach dieser Richtung angestellt. Aber leider kann man bei seiner Methode, welche ziemlich zuverlässig zu sein scheint, nur mit Blut arbeiten. Ist das Blut schon alt und die Verteilung der "Blutkörperchen im Blutplasma unregelmässig, so ist der Erfolg sehr stark schwankend. In der Praxis ist es sehr schwer, aus den Leichen von Ertrunkenen Blut zu gewinnen.

A. Kreidl, E. Lenk und vor diesen schon Goppelsraeder und Skraup führten Versuche zur Feststellung der Steighöhe von Menschen- und Tiermilch aus, und ich suchte diese Versuche für die Untersuchung vor Blut und Lungensaft bei Wasserleihen zu verwerten. Wenn man Filtrierpapier in Milch eintaucht, so kann man beobachten, dass die Milch vermöge ihrer Kapiilarität an dem Papier hinaufsteigt. Die Steighöhe der Milch ist abhängig von ihren Bestandteilen, wie Kasein, Fett etc. und ihrer Herkunft (Frauen- oder Tiermilch.)

Auf Grund dieser Kenntnis habe ich obiges Verfahren zunächst auf Blut angewendet. Wenn bei den Leichen von Ertrunkenen infolge der eingedrungenen Ertränkungsflüssigkeit das Blut des linken Herzens verdünnt wird, so werden das Blut des linken Herzens und das des rechten eine Differenz in den Steighöhen darbieten. Aber das Filtrierpapier ist nicht so empfindlich, um diesen Unterschied in den Steighöhen des Blutes vom linken und rechten Herzen deutlich anzuzeigen. Es kommt wohl in manchen Fällen vor, dass das Blut des linken Herzens etwas höher steigt als das des rechten, aber die Differenz beträgt meist nur I-2 $\mathrm{mm}$, und ist also, wenn man unvermeidliche Versuchsfehler berücksichtigt, zu geringfügig, um daraus einen Ertrinkungstod folgern zu können. Es kommen sogar manchmal Fälle vor, wo die Steighöhe des Blutes vom rechten Herzen grösser ist als die des Blutes vom linken. All dies hat seinen Grund in dem Mischungsverhältnis der Blutbestandteile; man muss deshalb bei 


\section{$-5-$}

praktischer Anwendung dieser Methode sehr vorsichtig zu Werke gehen.

In Würdigung dieser Erfahrung habe ich der Lunge eines Ertrunkenen Blut entnommen, in welchem natürlich mehr Ertränkungsflüssigkeit enthalten ist als im Herzblut, und ich kam auf den Gedanken, mit Lungensaft meine Experimente auszuführen.

\section{Untersuchungsmethode.}

Zur Vorbereitung nahm ich ein $100 \mathrm{~g}$ fassendes gewöhnliches Fläschchen mit einer ziemlich grossen Öffnung und einer Höhe von 8- Io $\mathrm{cm}$ und einen $2-3 \mathrm{~cm}$ breiten und $10-\mathrm{I} 5 \mathrm{~cm}$ langen Streifen Filtrierpapier und steckte diesen in das Fläschchen, bis sein Ende den Boden desselben berührte. Dann steckte jch durch den Streifen eine Nadel, deren Enden auf dem Rand des Glases auflagen, so dass der Streifen selbst frei hing (s. Abbildung). Als Untersuchungsmaterial verwendete ich das Blut einer Lunge, durch deren Hilus ich nach der üblichen Sektionsmethode drei bis vier grosse Schnitte machte. Hierauf liess ich diese Lunge abhängen, wodurch von den Schnittflächen das Lungenblut von selbst abträufelte. So ist es sehr leicht, IO-20 $\mathrm{ccm}$ Blut zu erhaiten. Dieser Lungensaft besteht aus Blut, Gewebsbestandteilen, Schleim und Ertränkungsflüssigkeit. Es ist darauf $\mathrm{zu}$ achten, dass von aussen kein Wasser sich dem gewonnenen Lungensaft beimenge, und es ist nicht nötig, zur Blutgewinnung irgendwelchen Druck auf die Lunge auszuüben. Fünf bis zehn $\mathrm{ccm}$ genügen für die Vornahme der Probe. Die so erhaltene Flüssigkeit gos' ich alsdann in das bereits erwähnte leere Fläschchen; dann hängte ich den Filtrierpapierstreifen in dasselbe hinein, und sogleich begann das Blut den Streifen hinaufzusteigen. Nach Io Minuten nahm ich das Filtrierpapier heraus, und ich presste es zwischen Fliesspapier, um das überflüssige Blut zu entfernen. Hierauf mass ich die Tiefe des Blutes im Fläschchen und markierte diese an dem Streifen. Der Einfachheit halber

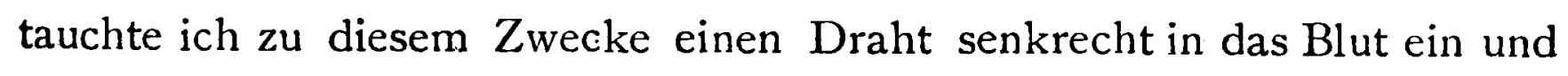
markierte, indem ich mit dem benetzten Draht am unteren Ende zu messen begann, an dem Streifen die Tiefe des Blutes mit einem Nadelstiche. 
Es gibt verschiedene Arten von Filtrierpapier, und der Erfolg richtet sich natürlich auch nach der jeweiligen Beschaffenheit des verwendeten Papiers. Für meinen Zweck gebrauchte ich Filtrierpapier , No. I 43" oder „Fn. $6.58 \times 58$ ", weil es nach meiner Erfahrung für meinen Zweck das beste ist, indem es die Differenz der Steighöhen von reinem und von mit Wasser verdünntem Blut im Gegensatz zu anderen Papierarten sehr deutlich zum Ausdruck bringt. Experimente mit gleichem Filtrierpapier und gleichem Blut ergeben stets das yleiche Resultat, und die Steighöhe des Blutes wird in keiner Weise durch die Breite des Streifens beeinflusst (s. Fig. A \& $A^{\prime}$ ), auch besteht keine wesentliche Differenz in den Steighöhen, wenn das Papier sehr tief oder nur wenig ins Blut eingetaucht wird (s. Fig. B \& $\mathrm{B}^{\prime}$ ).

Wenn der Papierstreifen mit dem Blut in Berührung kommt, so beginnt dasselbe aufzusteigen, und zwar während der ersten Sekunden schneller, dann langsamer und nach 5-6 Minuten nur noch unmerklich. Lässt man jedoch den Streifen längere Zeit, d. h. 50-60 Minuten im Blut stehen, so kann die Steighöhe eine sehr beträchtliche werden. Nach meiner Untersuchung erhält man die grösste Differenz der Steighöhen von reinem oder mit Wasser verdünntem Blut nach 7-8 Minuten. Lässt man dagegen das Papier länger, z. B. 20-30 Minuten im Blut stehen, so verringert sich die Differenz in den Steighöhen, und es kann dann reines Blut, wenn auch langsam, so doch ziemlich hoch steigen. Um vergleichbare Resultate $\mathrm{zu}$ erhalten, muss man daher eine bestimmte Zeitdauer in allen Versuchen einhalten. Ich habe nach einigen Vorversuchen als Normalzeitdauer 10 Minuten gewählt, weil nach dieser Zeit die Differenzen am ausgesprochensten sind.

Kreidl und Lenk hatten bei ihren Experimenten mit Milch das verwendete Filtrierpapier zuerst mit Wasserdampf gesättigt. Ich machte zum Vergleiche Versuche sowohl mit mit Wasserdampf gesättigtem als auch mit ungesättigtem Filtrierpapier, doch war kein besonderer Unterschied wahrnehmbar, weshalb ich mir bei meinen weiteren Versuchen diese Mühe sparte. Macht man anderseits das Experiment an einem dem Luftzug offenen Ort, so verflüchtigt sich der Wasserdampf des aufsteigender 
Blutes sehr schnell, und das weitere Aufsteigen wird erschwert. Meine Versuchsweise dürfte sehr zu empfehlen sein, weil hier der Filtrierpapierstreifen in einem verhältnismässig hohen Fläschchen hängt, dessen Innenraum naturgemäss stets eine gewisse Menge Feuchtigkeit enthält, weil von dem darin befindlichen Blut Wasserdampf aufsteigt. Es ist ferner $z \mathrm{u}$ beachten, dass der Streifen an den beiden Seiten die Wand des Fläschchens nicht berühren darf, weil dann das Blut an der mit der Wand in Berührung stehenden Stelle sehr hoch aufsteigen und den Erfolg des Versuchs beeinflussen wird.

In vielen Fällen, den Ertrinkungstod ausgenommen, beläuft sich die Steighöhe des Blutes im Minimum auf $4 \mathrm{~mm}$, in Maximum auf I I mm, im Durchschnitt auf 8,15 mm (s. Fig. C). Die Todesursachen in diesen Fällen waren ganz verschiedene.

Wenn ich solches Blut z. B. mit einer halben Menge physiologischer Kochsalzlösung vermischte, so vergrösserte sich die Steighöhe des Blutes zusehends, und diese betrug im Minimum I $2 \mathrm{~mm}$, im Maximum $20 \mathrm{~mm}$ und im Durchschnitt I6, I5 mm, also fast doppelt so viel wie bei unvermischtem Blut (s. Fig. $\mathrm{C}^{\prime}$ ). Nahm ich aber gleiche Mengen von Blut und Kochsalzlösung, so belief sich die Steighöhe im Minimum auf I $8 \mathrm{~mm}$, im Maximum auf $30 \mathrm{~mm}$ und im Durchschnitt auf 24, $8 \mathrm{~mm}$ (s. Fig. $\mathrm{C}^{\prime \prime}$ ).

Auch die Färbung des Filtrierpapiers durch das aufsteigende Blut ist von Wichtigkeit, und es lassen sich zwei Schichten unterscheiden. Die obere, schmale Zone ist immer stark rötlich gefärbt. In der zweiten, breiteren Zone ist die Färbung im allgemeinen schwächer, weil die roten Blutkörperchen hier nicht angereichert werden. Die unterste Schicht ist der Teil des Papierstreifens, welcher im Blut steht. Die erwähnten Schichten werden noch deutlicher sichtbar, wenn man den Filtrierpapierstreifen mit Fliesspapier abtrocknet und dadurch das überflüssige Blut wegnimmt. Wenn das Blut schon alt ist und die roten Blutkörperchen bereits aufgelöst sind (Haemolyse), so ist die Schichtbildung nicht mehr so klar erkennbar. Bei mit Wasser verdünntem Blut zeichnet sich die Schichtbildung sehr deutlich ab, und diese Erscheinung erleichtert einigermassen die Beurteilung, 
ob das Blut mit Wasser vermischt ist oder nicht.

Wenn man diese Methode bei dén Leichen Ertrunkener anwendet, so beträgt die Steighöhe des Blutes im Minimum $14 \mathrm{~mm}$ (s. Fig. D) und im Maximum $19 \mathrm{~mm}$ (s. Fig. $\mathrm{D}^{\prime}$ ). Natürlich ist die Menge der in die Lunge eingedrungenen Ertränkungsflüssigkeit nicht in allen Fällen die gleiche.

Ich habe einmal bei der Leiche eines Ertrunkenen, welche über zwei Monate im Wasser gelegen hatte und an welcher die Fäulnis bereits sehr weit fortgeschritten und der Lungensaft, wie es bei solchen Leichen gewöhnlich der Fall ist, infolge der Imbibitionsvorgänge im Thorax verschwunden war, mit dem Thoraxinhalt diese Probe gemacht. Im Thorax fand sich viel blutige Flüssigkeit vor, während in der Lunge nur wenig dickes Blut und auch ganz wenig Gas vorhanden waren. Die blutige Flüssigkeit stieg im Filtrierpapier bis $22 \mathrm{~mm}$ hoch, und die Färbung liess auch erkennen, dass die Flüssigkeit mit Wasser vermengt war. (Fall III. E. K., Selbstmord durch Ertrinken. Die Steighöhe der Flüssigkeit im Thorax siehe Fig.E).

Ferner versuchte ich diese Methode mit dem Blut von zwei Leichen, welche an der Thoraxwand schwere Verletzungen mit Ausgang in Verblutungstod durch Bluterguss in den Thorax darboten. Hier belief sich die Steighöhe des Blutes in dem einen Fall auf $13 \mathrm{~mm}$, in dem anderen Fall auf $25 \mathrm{~mm}$. Sie war also jedesmal grösser als normal, und besonders im letzteren Fall war eine Verdünnung des Blutes mit Lymphe und Thoraxflüssigkeit zu vermuten. Dieses Experiment machte ich bei Fall IV und IX, welche bereits angeführt sind.

Um die Einwirkung verschiedener Faktoren, wie Fäulnis, Verdünnung des Blutes etc. auch experimentell festzustellen, habe ich Versuche mit reinem Blut, mit reinem Blut und einer halben Menge Wasser und mit reinem Blut und Wasser zu gleichen Teilen unternommen und liess die drei Sorten Flüssigkeit drei bis vier Wochen in der Zimmertemperatur stehen. Das Blut zeigte natürlich hochgradige Fäulnis, und mikroskopisch waren fast keine Blutkörperchen, wohl aber kolossal viele verschiedene Fäulnisbakterien nachzuweisen. Bei diesen drei Versuchen stimmten die Resultate mit den mit frischem Blut gewonnenen ziemlich überein, nur dass sie eine 
geringe Abweichung in den Steighöhen zeigten, indem dieselben $2-3 \mathrm{~mm}$ niedriger waren (z. B. $6 \mathrm{~mm}$, $12 \mathrm{~mm}$ und $21 \mathrm{~mm}$ ). Diese drei Versuche. erbrachten mir den Beweis, dass die Fäulnis keinen besonderen Einfluss auf die Steighöhe des Blutes ausübt, und es ist mit Bestimmtheit anzuneh-' men, dass auf keinen Fall das faule Blut höher steigt als das frische (s. Fig. F). [s Für die praktische Anwendung der. Filtrierpapierprobe ist noch einiges zu bemerken. Gerinnt das zu verwendende Blut während der Unter-' suchung, so übt das natürlich einen' grossen Einfluss auf das Gelingen der Probe aus; denn in einem solchen Fall ist die in dem Filtrierpapier aufsteigende Flüssigkeit entwederr Serum mit nur ganz wenig Blutkörperchen oder reines Serum und erreicht eine sehr grosse Steighöhe, z. B. $53 \mathrm{~mm}$ (s. Fig. G), aber einen grossen Vorteil für die Praxis gewährt die Tatsache, dass man bei dem aus der Lungenschnittfäche gewonnenen Blut, besonders von Ertrunkenen so gut wie niemals das Gerinnen desselben zu befürchten hat.

Ferner ist sehr darauf zu achten, dass in das zur Probe bestimmite: Blut kein Fett hineingelangt, was sehr lejcht durch, Unvorsichtigkeit bei der Sektion geschehen kann. “Durch die Beimengung von Fett wird das Bild der Untersuchung auf dem . Filtrierpapier sein anderes, wie Fig: H zeigt. Die Blutkörperchen werden durch die Fettschicht zuerst abfiltriert, es steigt hauptsächlich nur Blutplasma in dem Filtrierpapier hinauf, und erst ganz allnählich gehen die Blutkörperchen noch weiter linauf, simmer aber in einem gewissen Abstand von der oberen Zone des aufgestiegenen Plasma:

Zuletzt müssen wir noch ein etwaigen Falls vorkommendes Lungenödem berücksichtigen, weil dieses ganz ähnliche Vorgänge darbietet. $ฯ$ Wenn das Ödem nur partiell in der Lunge vorhanden ist, so weist auch die Filtrierpapierprobe keine besondere Erscheinung auf, weil das Papier sich nicht so empfindlich zeigt. So war z. B.i Fall VIII. H. B. auch mit Miliartuberkulose und frischer adhaesiver Pleuritis verbunden. Bei allgemeinem Lungenödem, bei dem das der Lungenschnittfläche entnommene. Blut mit dem Exsudat stärker verdünnt ist, wie das von Ertrunkenen mit Ertränkungsflüssigkeit, ist die Steighöhe des Blutes auch grösser, als gewöhnlich (z. B. 
19-22 $\mathrm{mm}$ ), und in diesen Fällen kann man aus der Steighöhe keinen Schluss auf eine Verdünnung des Lungenblutes durch äussere Einwirkung ziehen (Fall XI. L. Z., Überfahrenwerden, Tod an Verblutung aus dem linken Bein. Der Verletzte, welcher in der chirurgischen Klinik behandelt wurde, starb nach einigen Tagen.) Allerdings schien mir in der Färbung des Filtrierpapiers eine gewisse Differenz aufzutreten. Das Filtrierpapier hatte beim Lungenödem, verursacht durch das Exsudat, eine stark gelbliche Färbung besonders in der zweiten Schicht, während es beim Lungensaft von Ertrunkenen nur rötlich gefärbt erscheint. Die Färbüng trat besonders in rischem Zustand des Papiers sehr deutlich hervor (s. Fig. J \& J'). Es erscheint mir nicht ausgeschlossen, dass man aus der Färbung darauf schliessen kann, ob das Blut von der Lunge eines an Lungenödem Erkrankten, oder ob es von der ödemfreien Lunge eines Ertrunkenen herrührt.

Ich hoffte, die Methode noch vereinfachen zu können und liess zu diesem $Z$ wecke einen Tropfen Blut auf das Filtrierpapier fallen. In diesem Versuch sollte nun das erhaltene Bild eigentlich das gleiche sein wie bei der oben beschriebenen Methode. In Wirklichkeit ist es jedoch schwer, das Volumen des Bluttropfens immer bestimmt zu halten; manchmal trocknet er auch sehr schnell auf dem Filtrierpapier, ein andermal wieder langsamer ein und verändert das Bild, weswegen diese Methode unsicher wird.

Der Erfolg des Experiments von Kreidl und Lenk mit Milch ist abhängig von dem Fett-Eiweiss- $/$ resp. Kaseingehalt derselben. Die Steighöhe des Blutes muss abhängig sein von der Viskosität zwischen Blutplasma und Blutkörperchen. Flüssiges Herzblut z. B. zeigt im allgemeinen in Io Minuten 6-8 mm Steighöhe. Wenn man nun dieses Herzblut zentrifugiert und nur das Blutplasma gebraucht, so erreicht man damit eine Steighöhe von 45-5 I mm (s. Fig. K). Schliesst man dagegen das Blut in einem geschlossenen Glas luftdicht ab, und lässt man es drei bis vier Wochen stehen, so tritt Fäulnis ein. Hat die Fäulnis nun sehr weit um sich gegriffen, so gibt es infolge Hämolyse dort keine Blutkörperchen mehr; trotzdem ist die Steighöhe sehr niedrig, z. B. $4-6 \mathrm{~mm}$. In diesem Blut haben sich kolossal viele Fäulnisbakterien entwickelt, und anstatt der 
Wiskósität zwischen. Blutkörperchen und,Blutplasma'besteht nur eire solche zwischen dem letzteren und den Bakterien, welche das Aufsteigen des Blutes erschweren. Anderseits ist die .Steighöhe! besonders. beträchtlich; wenn das Blut ganz frisch ist. Das lebend frische Blut vom Schwein, Pferd und Rind stieg $15-17 \mathrm{~mm}$ hoch. Als ich die Probe mit dem gleichen Blut nach 6-24 Stunden wiedérholte, bélief sich die Steighöhe auf nur 9- $10 \mathrm{~mm}$.

... Ich machte auch Versuche mit reinem Blut, dem 3\% Baryum chloricum zugesetzt waren, und verglich das Ergebnis mit dem von reinem Blut,

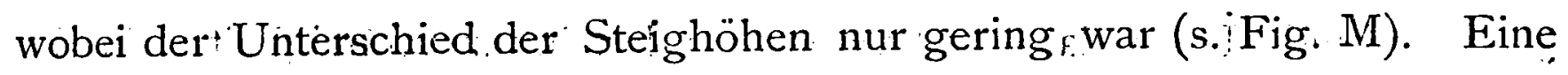
Erklärung für diese Erscheinung ist vielleicht die, dass in lebend frischem Blut die Blutkörperchen sehr elastisch sind und infolge desssen das Aufsteigen des Blutplasma mit den Blutkörperchen durch die ‘Zwischenräume der Filtrierpapierfasern hindurch sehr leicht ist.

Die Steighöhe, des Blutserums ist noch höher ${ }_{i j}$ als ${ }_{1}$ die des ${ }_{r}$ durch Zentrifugieren des Blutes erhaltenen Blutplasma, weil, beim Blutserum durch die Blutgerinnung Eiweiss wie Fibrinogen u. a.tentzogen wird. Sie beträgt 45-5 I mm.-Mengt man dem Blutserum oder Blutplasma noch Wasser bei, so nimmt die Steighöhe noch mehr zu. So zeigen z. B. Blutserum und Wasser zu gleichen Teilen eine Steighöhe von $66 \mathrm{~mm}$ (s. Fig. L): Wenn aber das. Blut diffus gerinnt, so ist die ${ }_{3}$ Steighöhe naturgemäss minimal, etwa nur 2-3 mm. Bei Experimenten mit reinem Blut, das zur Hälfte mit $8.5 \%$ iger Kochsalzlösung vermischt war, 'und ferner mit reinem Blut, dem, eine halbe Menge destillierten „Wassers beigemengt wurde, war die Steighöhe fast gleich (s. Fig. N \& O). Daraus darf man wohl schliessen, dass beim Blut von im Meerwasser Ertrunkenen die Steighöhe dieselbe sein wird, wie bei dem von im Süsswasser Ertrunkenen. In der Hauptsache ist die Steighöhe eben abhängig vom Wassergehalt des Blutes und von der Viskosität zwischen Blutplasma und Blutkörperchen.

Zum Schluss noch Folgendes: Der Ertrinkungstod lässt sich nach dieser Methode stets mit Sicherheit nachweisen. Die Methode ist für die Praxis sehr zu empfehlen, da sie sehr einfach auszuführen ist. Wenn man 
bei der Sektion eines Ertrunkenen die bei der Probe erhaltenen Filtrierpapierstreifen dem Protokoll beifügt, so hat man damit ein sicheres Zeugnis für den erwiesenen Ertrinkungstod.

\section{Literatur-Verzeichnis.}

I. Falk, Über den Tod im Wasser. Virchow's Archiv. XLVII.

2. Paltauf, Einige Bemerkungen über den Tod durch Ertrinken. Berliner Klin. Wochenschrift. I892. No. I 3.

3. Fagerlund, Über das Eindringen von Ertrinkungsflüssigkeiten in die Gedärme. Vierteljahrsschrift f. gerichtl. Medizin. Bd. LII. I890.

4. Wilmans, Über den Tod durch Ertrinken. Vierteljahrsschrift f. gerichtl. Medizin. Bd. XII. I 896.

5. Brouardel et Loye, Recherches expérimentelles sur la mort par submersion brusque. Arch. de Physiol. 1889. I, 2 et 3.

6. Lesser, Atlas der gerichtl. Medizin. II.

7. Hofmann, Lehrbuch der gerichtl. Medizin. I903.

8. Schmidmann, Handbuch der gerichtl. Medizin. 1907.

9. Skraup, Krause und Biehler, Über den capillaren Aufstieg von Säure.

Io. Kreidl und Lenk, Über das Aufsteigen von Menschen- und Tiermilch im Filtrierpapier. Zeitschrift f. Physiologie. Bd. XXIV. No. 25.

I I. Stumpf, Zur Diagnose des Todes durch Ertrinken. Vierteljahrsschrift f. gerichtl. Medizin. XLI. I9I I.

12. Bohne, Die Bedeutung der Stumpf'schen Methode für den Gerichtsarzt. Zeitschrift f. Medizinalbeamte. 24. Jahrg. No. I3. 


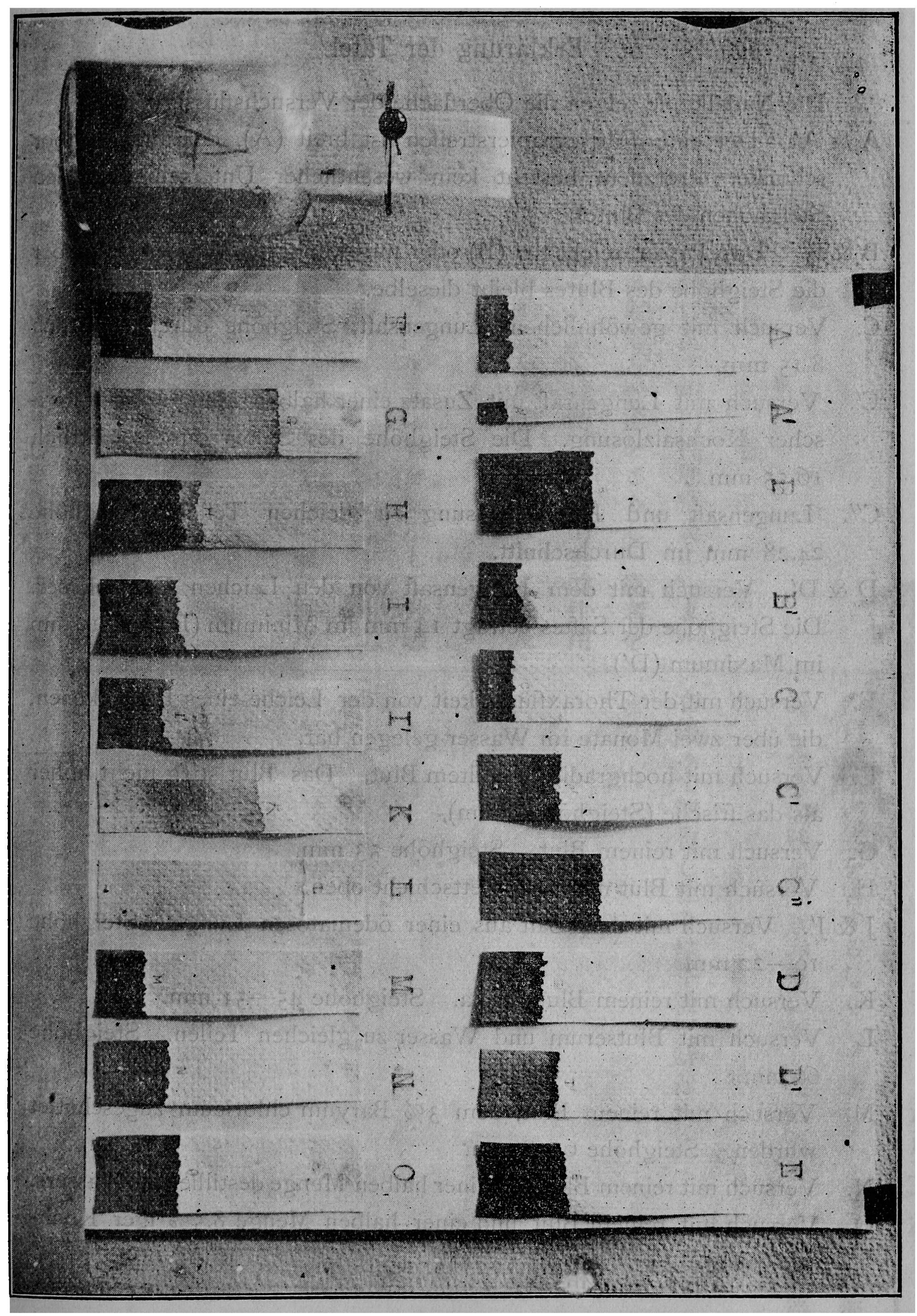




\section{Erklärung der Tafel.}

Die Nadelköpfe zeigen die Oberfläche der Versuchsflüssigkeiten.

A \& $\mathrm{A}^{\prime}$. Der eine Filtrierpapierstreifen ist breit (A), der andere aber schmäler; trotzdem besteht kein wesentlicher Unterschied in den Steighöhen des Blutes.

$\mathrm{B} \& \mathrm{~B}^{\prime}$. Das Papier reicht tief $(\mathrm{B})$ oder nur wenig ins Wasser $\left(\mathrm{B}^{\prime}\right)$, aber die Steighöhe des Blutes bleibt dieselbe.

C. Versuch mit gewöhnlichem Lungensaft, Steighöhe durchschnittlich $8.15 \mathrm{~mm}$.

$C^{\prime}$. Versuch mit Lungensaft mit Zusatz einer halben Menge physiologischer Kochsalzlösung. Die Steighöhe des Saftes durchschnittlich I $6.55 \mathrm{~mm}$.

$\mathrm{C}^{\prime \prime}$. Lungensaft und Kochsalzlösung zu gleichen Teilen. Steighöhe $24.28 \mathrm{~mm}$ im Durchschnitt.

$\mathrm{D} \& \mathrm{D}^{\prime}$. Versuch mit dem Lungensaft von den Leichen Ertrunkener. Die Steighöhe der Saftes beträgt $14 \mathrm{~mm}$ im Minimum(D) und $19 \mathrm{~mm}$ im Maximum $\left(\mathrm{D}^{\prime}\right)$.

E. Versuch mit der Thoraxflüssigkeit von der Leiche eines Ertrunkenen, die über zwei Monate im Wasser gelegen hat.

F. Versuch mit hochgradig gefaultem Blut. Das Blut stieg nicht höher als das frische (Steighöhe $6 \mathrm{~mm}$ ).

G. Versuch mit reinem Blut. Steighöhe $53 \mathrm{~mm}$.

H. Versuch mit Blut mit einer Fettschicht oben.

$\mathrm{J} \& \mathrm{~J}^{\prime}$. Versuch mit dem Saft aus einer ödematösen Lunge. Steighöhe $19^{--2} \mathrm{~mm}$.

K. Versuch mit reinem Blutplasma. Steighöhe 45-5 I mm.

L. Versuch mit Blutserum und Wasser zu gleichen Teilen. Steighöhe $66 \mathrm{~mm}$.

M. Versuch mit reinem Blut, dem 3\% Baryum chloricum zugeschüttet wurden. Steighöhe $6-8 \mathrm{~mm}$.

N. Versuch mit reinem Blut und einer halben Menge destillierten Wassers.

O. Versuch mit reinem Blut und einer halben Menge 8.5\% iger Kochsalzlösung. 